\title{
Neuroprotection in early stages of Alzheimer's disease is promoted by transthyretin angiogenic properties
}

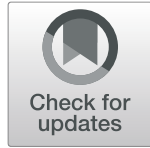

Tiago Gião ${ }^{1,2,3 \dagger}$, Joana Saavedra ${ }^{1,2 \dagger}$, José Ricardo Vieira ${ }^{1,2,4}$, Marta Teixeira Pinto ${ }^{1,5}$, Gemma Arsequell ${ }^{6}$ and Isabel Cardoso ${ }^{1,2,3^{*}}$ (D)

\begin{abstract}
Background: While still controversial, it has been demonstrated that vascular defects can precede the onset of other AD hallmarks features, making it an important therapeutic target. Given that the protein transthyretin (TTR) has been established as neuroprotective in $A D$, here we investigated the influence of $T T R$ in the vasculature.
\end{abstract}

Methods: We evaluated the thickness of the basement membrane and the length of brain microvessels, by immunohistochemistry, in AßPPswe/PS1A246E (AD) transgenic mice and non-transgenic mice (NT) bearing one $(T T R+/-)$ or two (TTR+/+) copies of the TTR gene. The angiogenic potential of TTR was evaluated in vitro using the tube formation assay, and in vivo using the chick chorioallantoic membrane (CAM) assay.

Results: $A D$ transgenic mice with $T T R$ genetic reduction, $A D / T R+/-$, exhibited a thicker $B M$ in brain microvessels and decreased vessel length than animals with normal TTR levels, $A D / T T R+/+$. Further in vivo investigation, using the CAM assay, revealed that TTR is a pro-angiogenic molecule, and the neovessels formed are functional. Also, TTR increased the expression of key angiogenic molecules such as proteins interleukins 6 and 8, angiopoietin 2, and vascular endothelial growth factor, by endothelial cells, in vitro, under tube formation conditions. We showed that while TTR reduction also leads to a thicker BM in NT mice, this effect is more pronounced in AD mice than in NT animals, strengthening the idea that $T R$ is a neuroprotective protein. We also studied the effect of TTR tetrameric stabilization on BM thickness, showing that AD mice treated with the TTR tetrameric stabilizer iododiflunisal (IDIF) displayed a significant reduction of BM thickness and increased vessel length, when compared to non-treated littermates.

Conclusion: Our in vivo results demonstrate the involvement of TTR in angiogenesis, particularly as a modulator of vascular alterations occurring in AD. Since TTR is decreased early in AD, its tetrameric stabilization can represent a therapeutic avenue for the early treatment of $A D$ through the maintenance of the vascular structure.

Keywords: Transthyretin, Alzheimer's disease, Basement membrane, Angiogenesis, Neuroprotection, TTR tetramer stabilizers, Chick chorioallantoic membrane (CAM) assay

\footnotetext{
* Correspondence: icardoso@ibmc.up.pt

†Tiago Gião and Joana Saavedra contributed equally to this work.

'i3S - Instituto de Investigação e Inovação em Saúde, Universidade do Porto, Rua Alfredo Allen 208, 4200-135 Porto, Portugal

${ }^{2}$ IBMC - Instituto de Biologia Molecular e Celular, Universidade do Porto, Rua Alfredo Allen 208, 4200-135 Porto, Portugal

Full list of author information is available at the end of the article
}

\section{$\triangle B M C$}

(c) The Author(s). 2021 Open Access This article is licensed under a Creative Commons Attribution 4.0 International License, which permits use, sharing, adaptation, distribution and reproduction in any medium or format, as long as you give appropriate credit to the original author(s) and the source, provide a link to the Creative Commons licence, and indicate if changes were made. The images or other third party material in this article are included in the article's Creative Commons licence, unless indicated otherwise in a credit line to the material. If material is not included in the article's Creative Commons licence and your intended use is not permitted by statutory regulation or exceeds the permitted use, you will need to obtain permission directly from the copyright holder. To view a copy of this licence, visit http://creativecommons.org/licenses/by/4.0/. The Creative Commons Public Domain Dedication waiver (http://creativecommons.org/publicdomain/zero/1.0/) applies to the data made available in this article, unless otherwise stated in a credit line to the data. 


\section{Introduction}

Alzheimer's disease (AD) patients undergo several neurovascular changes at different levels. Brain vascular dysregulation is the earliest and strongest factor during disease progression and is followed by amyloid- $\beta$ (A $\beta)$ peptide deposition, glucose metabolism dysregulation, functional impairment, and gray matter atrophy, in this order [1]. Decreased expression of the low-density lipoprotein receptor-related protein 1 (LRP-1) and Pglycoprotein (P-gp), as well as upregulation of the receptor for advanced glycation end products (RAGE), are mechanisms reported to be changed in AD patients, leading to $A \beta$ accumulation in the brain $[2,3]$. In addition to defective clearance mechanisms, increased endothelial pinocytosis, decreased number of mitochondria, decreased glucose transporter (GLUT)-1, and loss of tight/adherents junctions are features detected in AD [4]. The reduction of the capillary density is also characteristic of the AD brains [5]. This is due to an aberrant angiogenesis with premature pruning of capillary networks. This defective angiogenesis may be caused by a lack of angiogenic stimuli and unresponsive endothelium [6]. Although other authors describe increased vascular density in AD [7], the underlying angiogenic process has pathological characteristics. Some studies suggest that the promotion of angiogenesis results in concomitant blood-brain barrier (BBB) disruption and vessel leakiness [7]. Other studies defend that the vascular damage is a consequence of poor blood perfusion of the brain, leading to hypoperfusion/hypoxia causing the BBB dysfunction [8]. Other authors argue that the accumulation of $\mathrm{A} \beta$ in the walls of the capillaries can contribute to the reduced brain capillary density in $\mathrm{AD}$ via anti-angiogenic activity $[9,10]$. Another observed alteration in $\mathrm{AD}$ is the increased thickness of the vascular BM in AD [11]. Since the increase in BM thickness occurs before $A \beta$ deposition, it is speculated that it functions as a physical barrier to the $A \beta$ clearance across the BBB [12]. Some studies have related this BM thickening with increased collagen IV content, in AD and aging [13, 14].

Transthyretin (TTR), a $55-\mathrm{kDa}$ homotetrameric plasma and cerebrospinal fluid (CSF) protein, transports retinol through binding to the retinol-binding protein (RBP), which binds at the surface of TTR, and thyroxine (T4), which binds at a central hydrophobic channel formed at the dimer-dimer interface [15]. In the CSF, TTR is the main A $\beta$ binding protein [16], providing neuroprotection by avoiding $A \beta$ aggregation [16-23] and toxicity $[17,24]$, and by participating in $A \beta$ brain efflux at the BBB [25]. TTR is early decreased in AD, both in plasma [26-28] and in the CSF [29], probably due to its tetrameric instability $[26,30]$, hypothesized to result in accelerated clearance and lower levels. TTR instability is also a key feature in familial amyloid polyneuropathy
(FAP), a systemic amyloidosis that is usually caused by mutations in TTR. The amyloidogenic potential of the TTR variants is inversely correlated with its tetrameric stability [31], and the dissociation of the tetramer into monomers is at the basis of the events that culminate with TTR amyloid formation [32, 33]. TTR stabilization, used as a therapy in FAP [34, 35], can be achieved through the use of small-molecule compounds sharing molecular structural similarities with $\mathrm{T} 4$ and binding in the T4 central binding channel [36-38]. Although no TTR mutations have been found in AD patients [22], TTR stabilization has also been proposed as a therapeutic strategy to recover its ability to protect in AD [19, 39], and shown beneficial in a mouse model of AD [39, 40]. Iododiflunisal (IDIF), a potent TTR stabilizer, was administered to $\mathrm{AD}$ mice and bound plasma TTR displacing T4, resulting in decreased $A \beta$ amyloid burden and total A $\beta$ brain levels, and improved cognition [40]. Interestingly, TTR stabilization by IDIF improves TTR-assisted A $\beta$ brain efflux in vitro and enhanced the expression of LRP-1 in vivo [30]. The formation of TTR-IDIF complexes enhances BBB permeability of both IDIF and TTR, in vivo [41].

TTR has also been implicated in angiogenesis and the first reports of its involvement have been described in diseases such as FAP [42]; in diabetic retinopathy (DR) [43, 44], and lately, in cancer [45]. As reported, a study investigated the effect of TTR in angiogenesis by treating human umbilical vein endothelial cells (HUVECs) with wild-type (WT) TTR or a common FAP TTR mutant, V30M. The authors concluded that the TTR mutant inhibited cell migration and decreased survival relative to the WT TTR, by down-regulating several proangiogenic genes for angiopoietin-2 (Ang-2), vascular endothelial growth factor (VEGF) receptors 1 and 2, basic fibroblast growth factor (bFGF), and transforming growth factor-beta 2 (TGF- 32 ) [42]. In another study, to investigate how TTR affects the development of new vessels in DR, human retinal microvascular endothelial cells (hRECs) were cultured with TTR in natural and simulated DR environments (hyperglycemia and hypoxia). In the DR environment, TTR inhibited cell proliferation, migration, and tube formation, by repressing the expression of the pro-angiogenic genes Ang-2 and VEGF receptors 1 and 2 [43]. Conversely, in a low glucose environment, these angiogenesis-related features were improved by TTR. Recently, it was reported that TTR levels were increased in human serum of lung cancer patients. Additionally, TTR was shown able to promote tumor growth by enhancing several lung ECs functions as permeability, migration, and tube formation [45]. However, TTR potential in angiogenesis has never been addressed in vivo and the possible participation of TTR in brain angiogenesis and vascular alterations has never been elucidated. 
Taking these evidences into account, this work aimed at investigating the angiogenic potential of TTR and at assessing its involvement in the vascular impairment that occurs in $\mathrm{AD}$.

\section{Material and methods Animals}

Two mouse models were used in this work, an AD transgenic and a non-transgenic (NT) mouse model, both established in different TTR genetic backgrounds.

The AD mouse model AßPPswe/PS1A246E/TTR was generated by crossing the AD mouse model A PPPswe/ PS1A246E [46] (B6/C3H background) purchased from The Jackson laboratory with TTR-null mice (TTR-/-) (SV129 background) [47] as previously described [48]. F1 animals AßPPswe/TTR+/- and PS1A246E/TTR+/- were crossed to obtain A $\beta$ PPswe/PS1A246E/ TTR+/+, A $\beta$ PPswe/ PS1A246E/TTR+/-, AßPPswe/PS1A246E/TTR-/- and NT controls NT/TTR+/+, NT/TTR+/-, and NT-/-. The colony was maintained on a B6/C3H/SV129 genetic background. Hereafter, the AßPPswe/PS1A246E/TTR colony will be referred to as $\mathrm{AD} / \mathrm{TTR}$, and the different genotypes AßPPswe/PS1A246E/TTR+/+, AßPPswe/PS1A246E/TTR+/ -, and AßPPswe/PS1A 246E/TTR-/- referred to as $\mathrm{AD} /$ $\mathrm{TTR}+/+, \mathrm{AD} / \mathrm{TTR}+/-$, and $\mathrm{AD} / \mathrm{TTR}-/-$, respectively. Animals were housed in a controlled environment (12-h light/ dark cycles, temperature between 22 and $24^{\circ} \mathrm{C}$, humidity between 45 and 65\%, and 15-20 air changes/hour), with freely available food and water. All the above experiments were approved by the Institute for Research and Innovation in Health Sciences (i3S) Animal Ethics Committee and in agreement with the animal ethics regulation from Directive 2010/63/EU.

In order to study the role of TTR in collagen IV deposition or in vessel density, cohorts of littermates 7month-old female mice $\mathrm{AD} / \mathrm{TTR}+/+$ and $\mathrm{AD} / \mathrm{TTR}+/-$, cohorts of littermates 3-month-old female mice NT/ TTR $+/+$ and NT/TTR+/- and one cohort of 3-monthold female mice $\mathrm{AD} / \mathrm{TTR}+/$ - were used. $\mathrm{AD} / \mathrm{TTR}+/-\mathrm{fe}-$ male control mice or treated with IDIF [40] for 2 months (from 5- to 7-month-old), were used to investigate the relevance of TTR stabilization in collagen type IV levels, in AD.

\section{Collagen IV immunohistochemistry}

Free-floating 30- $\mu \mathrm{m}$-thick coronal brain sections of mice were permeabilized with $0.25 \%$ Triton $\mathrm{X}-100$ in phosphate-buffered saline (PBS) for $10 \mathrm{~min}$ at room temperature (RT), blocked with $5 \%$ bovine serum albumin (BSA) in PBS for $1 \mathrm{~h}$ at RT and incubated with primary rabbit anti-collagen IV antibody (1:100) (Abcam) in $1 \%$ BSA in PBS overnight at $4{ }^{\circ} \mathrm{C}$. Next, sections were washed with PBS and incubated with Alexa Fluor-568 goat anti-rabbit IgG antibody (1:2000) for $1 \mathrm{~h}$ at RT. All steps were performed with agitation. To remove tissue autofluorescence, sections were covered with Sudan black B solution $(0.3 \%$ Sudan black B in $70 \%$ ethanol) applied for $5 \mathrm{~min}$ at RT, followed by multiple washing steps with PBS at RT with agitation. The brain sections were dried for $20 \mathrm{~min}$ at RT and mounted on $0.1 \%$ gelatin-coated slides with Fluoroshield ${ }^{\mathrm{TM}}$ with DAPI (Sigma-Aldrich). Sections were visualized and photographed using a Zeiss Axio Imager Z1 microscope equipped with an Axiocam MR3.0 camera and Axivision 4.9.1 software. A total of twenty-thirty randomly selected vessels in the hippocampus and cortex of each mouse was photographed at $\times 100$ magnification, and the ratio intensity/area was measured using the ImageJ software.

To assess the vascular density of mice brains, $30-\mu \mathrm{m}$ thick coronal brain sections were boiled at $90^{\circ} \mathrm{C}$ in citrate buffer for $15 \mathrm{~min}$ for antigenic recovery and then washed with $0.3 \%$ Triton X-100 in PBS for 10 min at RT. Tissues were blocked/permeabilized with a solution of $1 \%$ BSA and $0.5 \%$ Triton X-100 in PBS, overnight at $4{ }^{\circ} \mathrm{C}$. The coronal sections were then incubated for $72 \mathrm{~h}$ at $4{ }^{\circ} \mathrm{C}$ with primary rabbit anti-collagen IV antibody (1: 200) (Abcam) in a solution with $1 \%$ BSA, $0.5 \%$ Triton $X-$ 100 , and $2 \%$ fetal bovine serum (FBS) in PBS. After, tissues were washed with $0.3 \%$ Triton X-100 in PBS at $4{ }^{\circ} \mathrm{C}$. Next, sections were incubated with Alexa Fluor-568 goat anti-rabbit IgG antibody (1:500) overnight at $4{ }^{\circ} \mathrm{C}$, followed by washing with $0.3 \%$ Triton X-100 in PBS and then dried for $20 \mathrm{~min}$ at RT and mounted on silane precoated slides with Fluoroshield ${ }^{\mathrm{TM}}$ with DAPI (Sigma-Aldrich). Sections were visualized and photographed using a Zeiss Axio Imager Z1 microscope equipped with an Axiocam MR3.0 camera (Carl Zeiss) and Axiovision SE64 Rel. 4.9.1 software. A total of twenty-twenty five fields of view were randomly selected from the cortex and hippocampus of each brain section and photographed at $\times 20$ magnification. The total length of the blood vessels per field was measured using the ImageJ software.

\section{Production and purification of human recombinant TTR} Human recombinant WT TTR (rec TTR) was produced in a bacterial expression system using Escherichia coli BL21 [49] and purified as previously described [50]. Briefly, after growing the bacteria, the protein was isolated and purified by preparative gel electrophoresis after ion exchange chromatography. Toxin-free TTR was obtained using the Detoxi-Gel Endotoxin Removing Gel (Thermo), following the manufacturer's instructions. Analyses of the protein were performed by SDS-PAGE, western blot, and native PAGE.

\section{Purification of human TTR from sera}

Human plasma from donors who were informed of the purpose of the study and gave their written consent were 
collected in accordance with the approved guidelines. Samples were subjected to affinity chromatography to isolate human TTR (hTTR); for this, we used $1 \mathrm{~mL}$ column of NHS-activated Sepharose coupled to rabbit antihuman TTR (Dako). The column was washed with PBS and then incubated with $500 \mu \mathrm{L}$ of human plasma for 2 $h$ at RT. To elute TTR from the column, $5 \mathrm{~mL}$ of Gentle $\mathrm{Ag} / \mathrm{Ab}$ elution buffer (Thermo Scientific) were applied, and $1 \mathrm{~mL}$-aliquots were collected and OD $280 \mathrm{~nm}$ was registered.

\section{Cell culture}

The immortalized human cerebral microvascular endothelial cell line, hCMEC/D3 (Tebu-Bio) is a wellcharacterized in vitro model of BBB. The hCMEC/D3 cells were used between passage 25 and 35 and cultured following the available data sheet. All culture flasks were coated with rat tail collagen type I solution (Sigma) at a concentration of $150 \mu \mathrm{L} / \mathrm{mL}$ and were incubated for $2 \mathrm{~h}$ at $37^{\circ} \mathrm{C}$. Cells were cultured in EBM-2 medium (Lonza) containing 5\% FBS (Gibco), 1\% of penicillin-streptomycin (Lonza), $1.4 \mu \mathrm{M}$ of hydrocortisone (Sigma-Aldrich), $5 \mu \mathrm{g} / \mathrm{mL}$ of ascorbic acid (Sigma-Aldrich), 1\% of chemically defined lipid concentrate (Gibco), $10 \mathrm{mM}$ of 4-(2-hydroxyethyl)-1-piperazine-1-ethanesulfonic acid (HEPES) (Gibco) and $1 \mathrm{ng} /$ $\mathrm{mL}$ of human bFGF (Sigma-Aldrich). Cells were incubated at $37^{\circ} \mathrm{C}$ in a humidified atmosphere with $5 \%$ of $\mathrm{CO}_{2}$. Cell culture medium was changed every 2-3 days.

\section{Tube formation assay}

hCMEC/D3 cells, grown in $25 \mathrm{~cm}^{2}$ flasks, at a confluence of $80-90 \%$ were incubated for $24 \mathrm{~h}$ with EBM-2 medium (Lonza) containing 1\% FBS (Gibco) (negative control), with bFGF $(35 \mathrm{ng} / \mathrm{mL}$ ) (positive control), or with rec TTR at different concentrations $(10,25,250$, $500 \mathrm{nM}$, and $1 \mu \mathrm{M}$ ) or with hTTR $250 \mathrm{nM}$. Then, cells were transferred into 96-well plates, previously coated with Matrigel (Corning), and grown in the same conditions of media, bFGF or TTR for another $9 \mathrm{~h}$. Then, cells were photographed using the In Cell Analyzer 2000 (GE Healthcare) (magnification $\times 10$ ). The supernatants were collected, centrifuged at $14.000 \mathrm{rpm}$ for $10 \mathrm{~min}$ and stored at $-20^{\circ} \mathrm{C}$. Each condition was performed in triplicate and experiments were repeated three times.

\section{Quantification of angiogenesis-related proteins}

The angiogenesis-related proteins interleukins 6 and 8 (IL-6, IL-8), angiopoietin 1 and 2 (Ang-1, Ang-2), epidermal growth factor (EGF), basic fibroblast growth factor (bFGF), platelet endothelial cell adhesion molecule (PECAM-1), placental growth factor (PlGF), VEGF and tumor necrosis factor $\alpha$ (TNF- $\alpha$ ) were quantified in the supernatants collected from hCMEC/D3 grown under conditions of tube formation in the presence of media alone or with $1 \mu \mathrm{M}$ rec TTR, using the LEGENDplex Human Angiogenesis Panel (BioLegend) bead-based immunoassay. The assay was performed according to the manufacturer's recommendations. Analysis was performed using a BD Accuri C6 (BD Biosciences) and LEGENDplex $^{\mathrm{TM}}$ Data Analysis software v8.0 (BioLegend).

\section{ELISA analysis for IL-6}

IL-6 was also quantified in the supernatants collected from hCMEC/D3 cells used for the tube formation, in the presence of media alone or with rec TTR at different concentrations $(10,25,250 \mathrm{nM}$, and $1 \mu \mathrm{M})$, using a LEGEND MAX ${ }^{\mathrm{su}}$ Human IL-6 Sandwich Enzyme-Linked Immunosorbent Assay (ELISA) Kit (BioLegend) with pre-coated plates. The assay was performed according to the manufacturer's recommendations. Analysis was performed using Synergy Mx and by measuring absorbance at 450 and $570 \mathrm{~nm}$. A standard curve was generated for IL-6 from $7.8 \mathrm{pg} / \mathrm{mL}$ to $500 \mathrm{pg} / \mathrm{mL}$.

\section{Angiogenesis chick chorioallantoic membrane (CAM) assay}

Commercially available fertilized chick (Gallus gallus) eggs were horizontally incubated at $37{ }^{\circ} \mathrm{C}$, in a humidified atmosphere. On embryonic development day (EDD) 3 , a square window was opened in the shell after removal of $1.5-2 \mathrm{~mL}$ of albumen, to allow detachment of the developing CAM. The window was sealed with a transparent adhesive tape and eggs re-incubated. On EDD10, rec TTR $(1 \mu \mathrm{M})$, hTTR $(1 \mu \mathrm{M})$, PBS (vehicle, negative control) and bFGF $(50 \mathrm{ng} / \mu \mathrm{L}$, positive control) were placed on top of the CAM, into $3 \mathrm{~mm}$ silicone rings, under sterile conditions (1 condition per egg). Eggs were re-sealed and returned to the incubator for an additional $72 \mathrm{~h}$. On EDD13, rings were removed, the CAM was excised from embryos and photographed exovo under a stereoscope, using a $\times 20$ magnification (Olympus, SZX16 coupled with a DP71 camera). The number of new vessels $(<20 \mu \mathrm{m}$ diameter $)$ growing radially towards the inoculation area was counted in a blind fashion manner.

\section{In vivo analysis of vascular permeability}

The CAM model was also used to evaluate vascular permeability or vessel leakage, as a measure of TTRinduced neo-vessels functionality. Embryos were cultured ex ovo. To prepare shell-less CAM, eggs were incubated as described above and on EDD3, the content of the egg was transferred to sterile weigh boats, covered with square Petri dishes, and returned to the incubator for additional 7 days. At EDD10, $10 \mu \mathrm{l}$ of PBS, rec TTR $(1 \mu \mathrm{M})$ and VEGF $(4 \mathrm{ng} / \mu \mathrm{L})$ were inoculated on distinct sites of the same egg, twice each, into $3 \mathrm{~mm}$ silicone rings under sterile conditions. Three independent 
experiments were performed summing a total 16 CAM sites/condition (8 eggs). After 3 days (EDD13), chicken embryos were injected intravenously with $100 \mathrm{ul} \mathrm{of} \mathrm{Ev-}$ ans Blue Dye (EBD, Sigma) solution (0.5\% EBD, 5\% BSA in PBS) and further incubated for $60 \mathrm{~min}$. After incubation, embryos were perfused with saline. The tissue underlying the rings (inoculation sites) was removed, cleaned in saline, blotted dry, weight, homogenized, and incubated in $200 \mathrm{ul}$ of formamide (Sigma), at $38{ }^{\circ} \mathrm{C}$ for $48 \mathrm{~h}$, to release the extravasated dye. The samples were centrifuged and $175 \mu \mathrm{l}$ of supernatant was quantified spectrophotometrically at $620 \mathrm{~nm}$. The amount of EBD in the experimental samples was calculated by interpolating to a standard curve and the concentration of EBD per $g$ of tissue was determined.

\section{Statistical analysis}

All quantitative data were expressed as mean \pm standard error of the mean (SEM). Initially, data was assessed whether it followed a Gaussian distribution. In the cases of non-Gaussian distribution comparisons between two groups were made by non-parametric Kruskal-Wallis test and comparisons between two groups were made by Student's $t$ test with a Mann-Whitney test.

When found to follow a Gaussian distribution, differences among conditions or groups were analyzed by one-way ANOVA with the appropriate post hoc pairwise tests for multiple comparisons tests. Differences in CAM assay and IL-6 Elisa kit were analyzed using one-way ANOVA followed by Tukey's multiple comparison test. P-values lower than 0.05 were considered statistically significant. Statistical analyses were carried out using GraphPad Prism 8 software for Windows.

\section{Results}

\section{TTR influences vascular features in the mouse brain} For this work we used AD/TTR+/+, AD/TTR+/-, NT/ TTR $+/+$, and NT/TTR $+/-$ animals. We did not analyze the respective TTR-/- animals, although we obtained them in the course of breeding, to avoid indirect effects of TTR-deficiency, including compensatory processes, that could confound our interpretations. Additionally, the TTR+/- animals, in particular, the $\mathrm{AD} / \mathrm{TTR}+/-$, are a better representation of the behavior of TTR in AD, since TTR is decreased in this pathology but not absent.

\section{Reduction of TTR increases the thickness of the collagen IV layer in brain microvessels of $A D$ mice}

To investigate a possible relationship of TTR reduction with the thickening of the $\mathrm{BM}$ and with the structural vascular alterations reported in $\mathrm{AD}$, we evaluated collagen IV levels in brain microvessels, in the $\mathrm{AD} / \mathrm{TTR}$ mouse model. This model established in different TTR genetic backgrounds [48], bears two AD-related transgenes (APP and PSEN1) and A $\beta$ deposition starts at around 6 months [48]. In comparison to males, females present a more severe form of AD-like disease, thus in this study we used 7-month-old female animals. AD/TTR+/- females were compared to littermates with normal TTR expression, $\mathrm{AD} / \mathrm{TTR}+/+$. Our results revealed a significantly thicker collagen IV layer in 7-months old $\mathrm{AD} / \mathrm{TTR}+/-$ as compared to $\mathrm{AD} / \mathrm{TTR}+/+$ animals, both in cortex and in hippocampus microvessels (Fig. 1 A1). Altogether, our results implicate TTR in vascular processes, which are known to be early dysregulated in AD.

\section{Reduction of TTR decreases the length of brain microvessels in $A D$ mice}

To understand if TTR affects other cerebrovascular features and if the effect observed at the level of the BM is related to angiogenesis, we measured brain vascular density in the same animals.

Both cortex and hippocampus were analyzed and our results show that, in the hippocampus, reduction of TTR resulted in decreased vessel length in $\mathrm{AD} / \mathrm{TTR}+/$ - mice as compared to $\mathrm{AD} / \mathrm{TTR}+/+$ (Fig. $1 \mathrm{~A} 2$, right panels). In the cortex, the differences were not statistically significant (Fig. 1 A2, left panels). These observations support the results obtained for the BM thickness and further implicate TTR in angiogenesis, especially in the hippocampus, a particularly relevant brain area in the initial stages of $\mathrm{AD}$.

\section{Reduction of TTR increases the thickness of the collagen IV layer in brain microvessels of young non-transgenic mice} Although our results suggest that TTR influences the thickness of the BM, in particular the collagen IV layer, we could not determine if the effect was direct or indirect. One hypothesis is that high levels of $A \beta$, as it happens in $\mathrm{AD}$, either due to increased production, reduced elimination or both, could be responsible for the increase in collagen IV. It is possible that $\mathrm{AD} / \mathrm{TTR}+/$ - mice show increased amount of collagen IV because less TTR is available to interact with and to eliminate $A \beta$.

Thus, in order to unravel this question, we compared collagen IV levels in non-transgenic (NT) littermate mice with two different TTR backgrounds, NT/TTR+/+ and NT/TTR+/- allowing to understand if TTR is directly involved. Furthermore, this evaluation was performed at the age of 3 months, which in this specific AD model is prior to amyloid deposition [48]. Results presented in Fig. 1B clearly show that NT/TTR+/- mice presented significantly higher levels of collagen IV in brain microvessels of both the cortex and hippocampus, as compared to NT/TTR $+/+$ animals, thus suggesting that it is, in fact, a direct effect of TTR. 


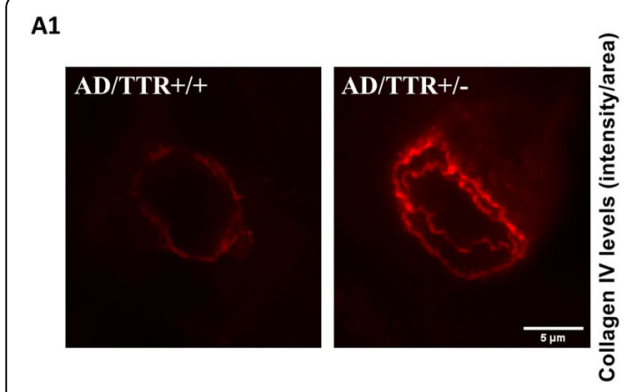

A2
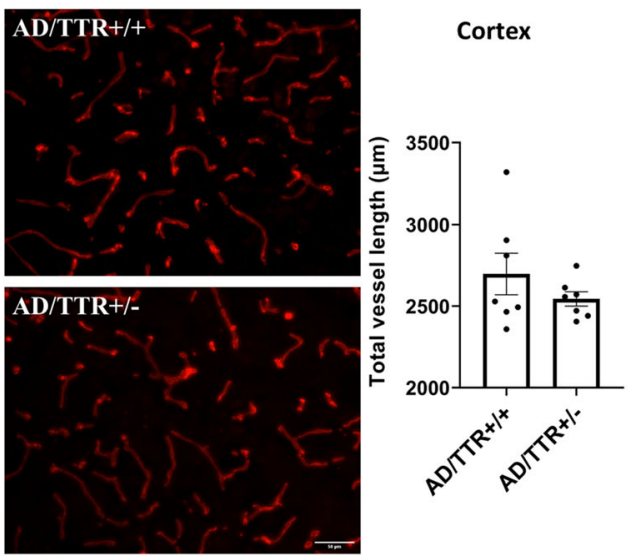

Cortex

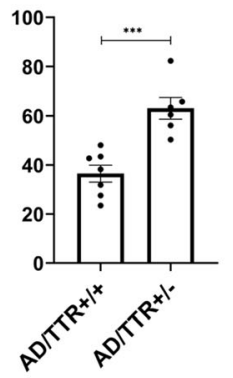

AD/TTR+ + +
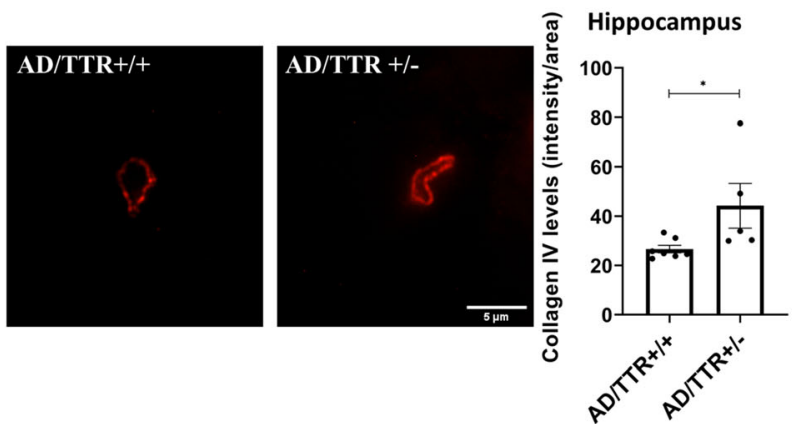

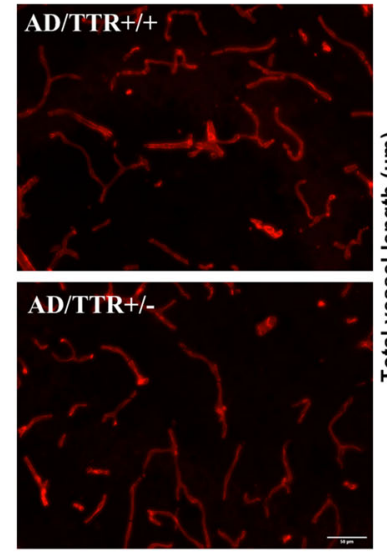

Hippocampus
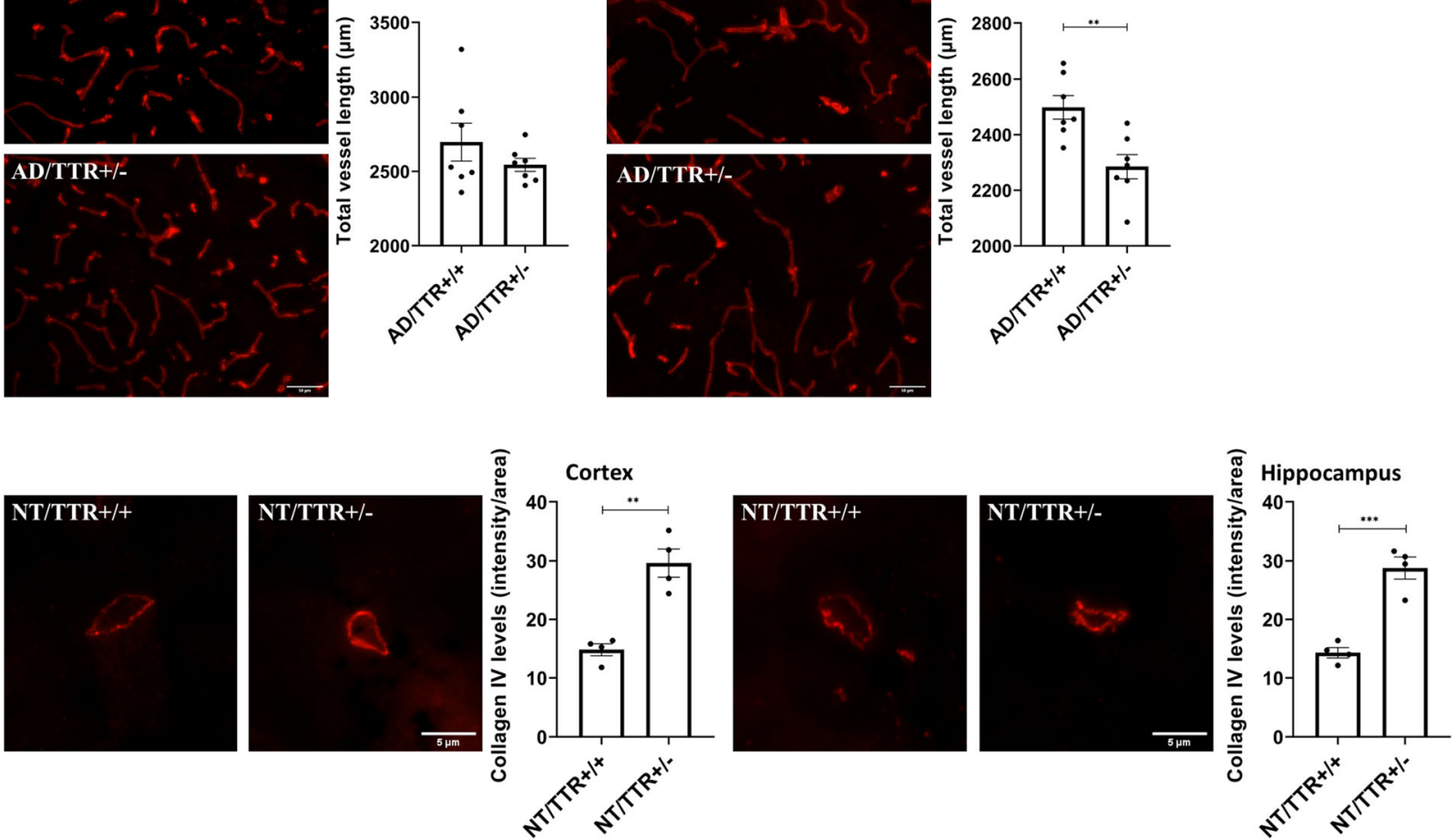

Fig. 1 Effect of TTR reduction in vascular features in mice brain microvessels. A1 Representative images and quantification plots of collagen IV (red) levels in the BM of cortex and hippocampus vessels derived from 7-month-old AD mice with different TTR genetic backgrounds, AD/TTR/ $+/+(n=7)$ and AD/TTR+/- ( $n=6$ for cortex; $n=5$ for hippocampus), showing significantly increased levels in microvessels from AD/TTR+/compared to $\mathrm{AD} / \mathrm{TTR}+/+$ mice. Scale bar $=5 \mu \mathrm{m}$. A2 Representative images and quantification plots of the length of brain vessels, as evaluated by collagen IV staining, from 7-month-old AD mice with different TTR genetic backgrounds, AD/TTR/+/+ $(n=7)$ and AD/TTR+/- $(n=7)$, showing significantly decreased vessel length in the hippocampus of $A D / T R+/-$ compared to $A D T T R+/+$. Scale bar $=50 \mu m$. B Representative images of the cortex and hippocampus and quantification plots of collagen IV immunostaining in microvessels of NT/TTR+/+ and NT/TTR+/- 3-month-old mice, showing an increase in collagen IV content in NT/TTR+/- mice $(n=4)$ relative to NT/TTR+/+ littermates $(n=4)$. Scale bar $=5 \mu \mathrm{m}$. Data are expressed as mean \pm SEM. ${ }^{*} p<0.05 ;{ }^{* *} p<0.01 ;{ }^{* *} p<0.001$

TTR possesses angiogenic activity

\section{TTR promotes tube formation by hCMEC/D3 cells}

The tube formation assay is a powerful in vitro test encompassing EC adhesion, migration, protease activity and tube formation (capillary-like structures). Thus, and to explore the angiogenic activity of TTR, endothelial cells of human brain origin, hCMEC/D3 cells, grown under tube formation-conditions, on Matrigel, were incubated with different concentrations of rec TTR. The results are displayed in Fig. 2A, A' and Supplementary Figure 2, and reveal that TTR affects the tube formation processes in a dose dependent-manner. Concentrations of TTR equal or above $250 \mathrm{nM}$ result in a significantly higher area covered by the capillary-like structures, as compared to the negative control. These TTR concentrations are well below their physiologic concentration 


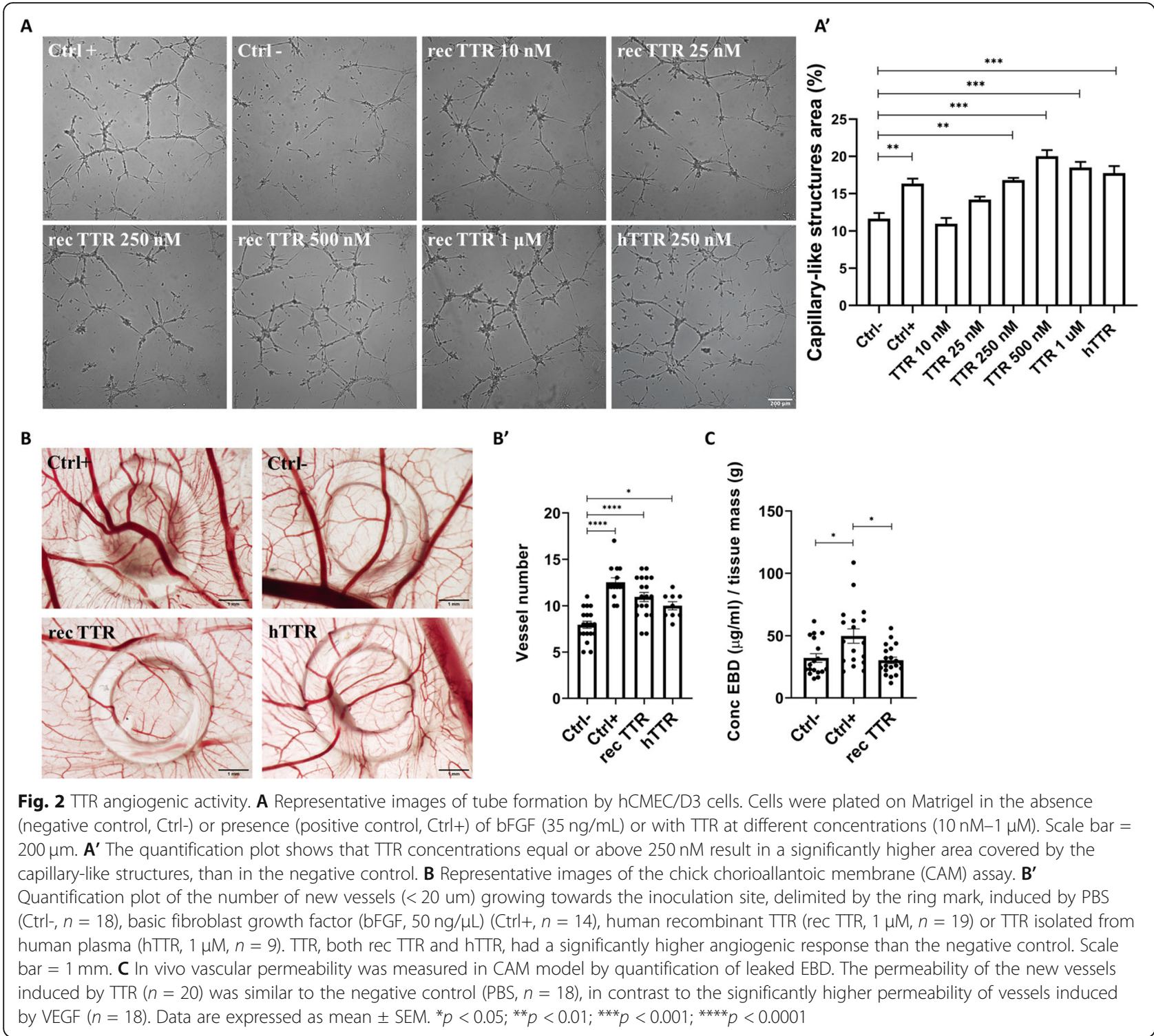

in plasma and are similar to their concentration in the CSF. To confirm that the angiogenic effect was indeed provided by TTR, thus excluding the possibility of contaminants associated with the protocol of recombinant protein purification from bacteria, TTR isolated from human serum (hTTR) was also evaluated, and results corroborated the angiogenic activity of TTR (Fig. 2A, $\left.\mathrm{A}^{\prime}\right)$. As for TTR species present in the preparations, the TTR tetramer was the only form detected, evaluated in native gel (Supplementary Figure 1).

\section{TTR is angiogenic in vivo and the neovessels formed are functional}

To further confirm the angiogenic activity of TTR, we used the CAM assay. Both rec TTR and hTTR were tested and at $1 \mu \mathrm{M}$ induced a significantly higher angiogenic response than the negative control, as deduced by the higher number of detected new vessels (vessels with a diameter under $20 \mathrm{um}$ ) (Fig. 2B, B'). TTR angiogenic response was comparable to the positive control (bFGF), in particular for the rec TTR.

Also using the CAM in vivo model, we studied the permeability of the TTR-induced vessels, by quantifying the leakage of EBD. This assay indicated that the permeability of TTR-induced vessels is comparable to the negative control (PBS), and significantly different from the positive control (VEGF) (Fig. 2C). It can be inferred that TTR-induced neovessels are functional (in contrast with leakier vessels induced by VEGF). 
TTR regulates angiogenic molecules

To further explore the molecular mechanisms underlying the angiogenic activity of TTR, supernatants of hCMEC/D3 cells grown under tube-formation conditions, in the presence of rec TTR $(1 \mu \mathrm{M})$ or with media alone, were used to identify key targets involved in angiogenesis which could be affected by TTR.

Among the ten molecules analyzed, IL-6, IL-8, Ang-2, and VEGF were differentially overexpressed in the presence of TTR, whereas the remaining six presented concentrations below the detection limit. As shown in Fig. 3A, the expression of detected molecules was significantly increased relative to the negative control when stimulated with rec TTR $(1 \mu \mathrm{M})$ indicating that TTR acts as a pro-angiogenic molecule by increasing the expression of those molecules. It is possible that TTR affects other angiogenic molecules, possibly even those that were undetected by the current approach.
We also confirmed the effect of IL-6 using an ELISA approach and as can be appreciated in Fig. 3B it is clear a dose-response effect as TTR concentration is increased. While at $10 \mathrm{nM}$ the differences are not significant, TTR concentrations between $25 \mathrm{nM}$ and $1 \mu \mathrm{M}$ lead to significantly increased expression of IL-6, as compared to the negative control. These results are also in line with those of the tube formation assay (Fig. 2A').

\section{The impact of TTR reduction on BM thickening is greater} in $A D$ than in NT mice

To understand if TTR reduction impacts differently in an $\mathrm{AD}$ and in a non-AD environment, we analyzed the effect of the same TTR reduction on the collagen IV layer, in the $\mathrm{AD}$ and in the NT backgrounds (NT/ TTR+/- versus AD/TTR+/-). Figure 4 depicts the results obtained and shows that the impact of TTR reduction is greater in an AD-like environment in the

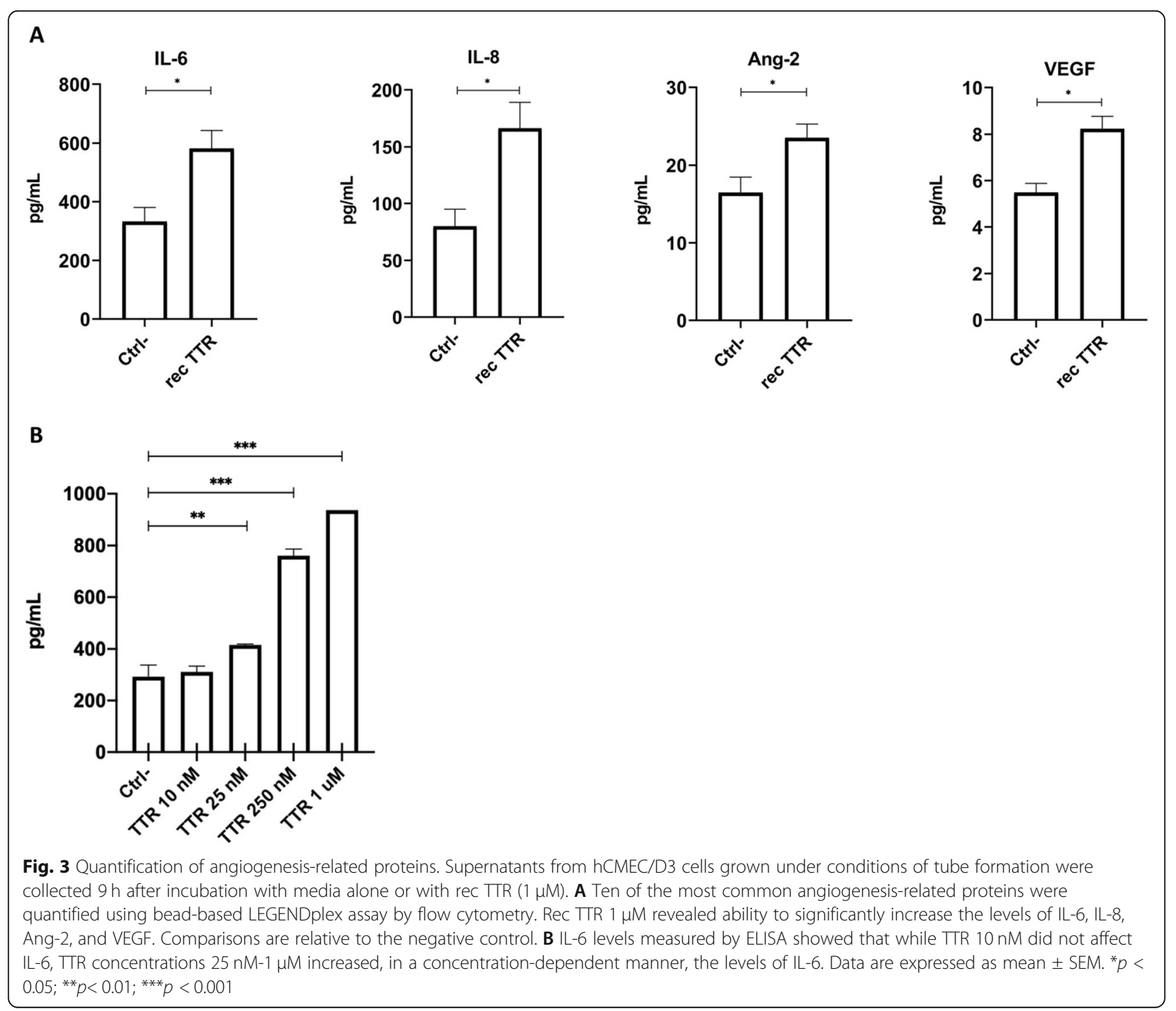




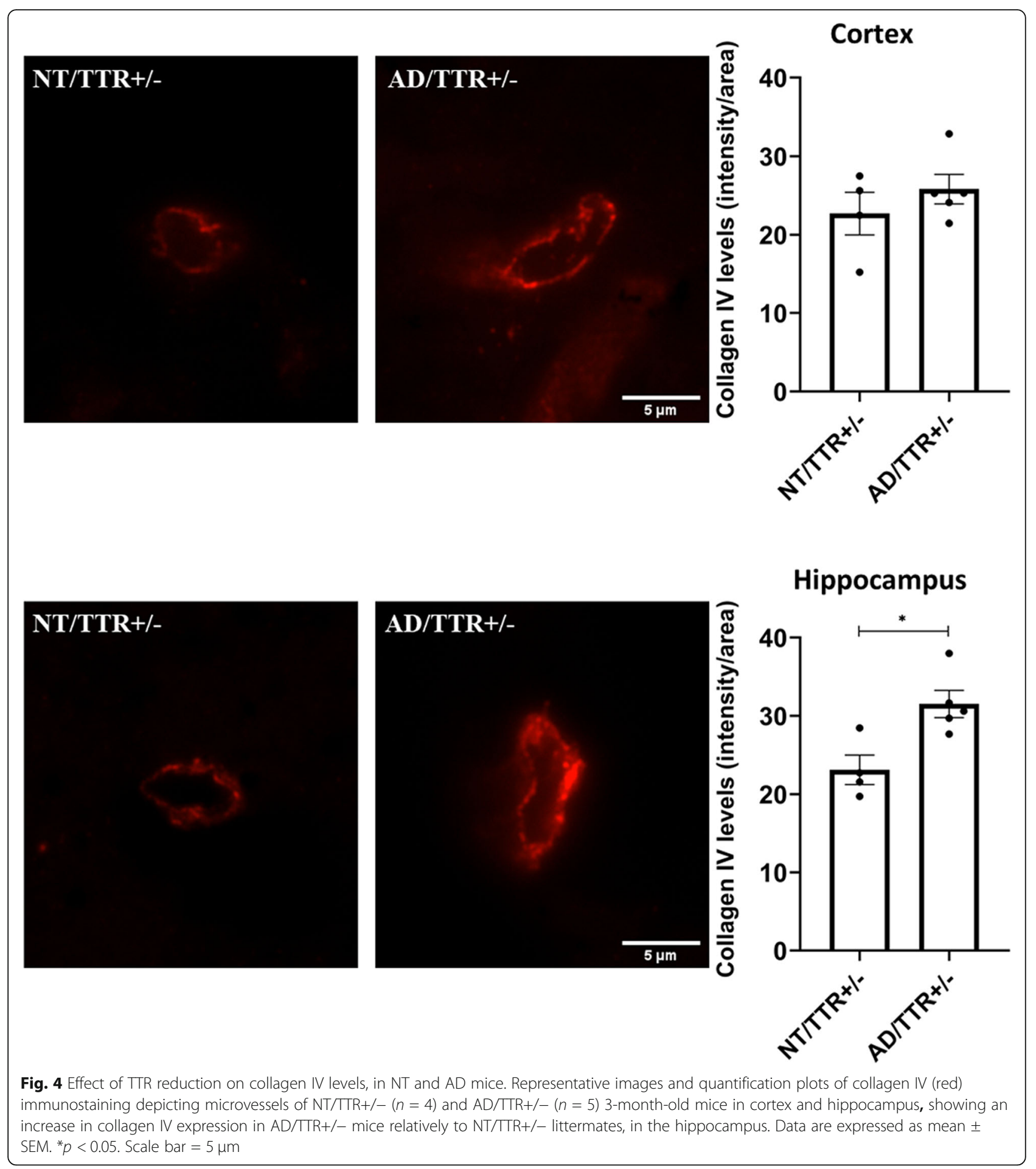

hippocampus, further corroborating the neuroprotective function of TTR in AD. Given that these are 3-monthold animals and that, in this model, deposition begins at around 6 months, our results support other findings that suggest brain vascular dysregulation as the earliest factor during the disease progression.
TTR stabilization results in decreased thickness of the collagen IV layer in brain microvessels of AD mice

So far, in this work, we have shown that TTR reduction worsens $\mathrm{AD}$ features in mice, such as BM thickening. To further investigate a possible neuroprotective effect of TTR in the vascular context, and given that TTR 
stabilization is used to improve its activity, we analyzed the $\mathrm{BM}$ thickness in brain microvessels in $\mathrm{AD}$ mice treated with one TTR stabilizer, IDIF. Administration of IDIF to AD mice from the age of 5- to 7-month-old, resulted in amelioration of some AD features, such as the cognitive function and decreased $A \beta$ brain levels [40].

In this work, we used brain slides obtained in our previous study, above mentioned [40], and performed collagen IV staining to assess BM thickness and vessels length in $\mathrm{AD} / \mathrm{TTR}+/-$ animals, non-treated versus IDIF-treated. As depicted in Fig. 5, AD/TTR+/- mice treated with IDIF presented a significant reduction in the BM thickness in the cortex and hippocampus, and an increase in vessel length in the hippocampus, as compared to non-treated animals. Altogether, these results indicate that TTR stabilization might be a therapeutic target for early treatment in AD.

\section{Discussion}

TTR is a homotetrameric protein typically known as a carrier of T4 and retinol in plasma and CSF. During the last years, several functions have been attributed to this protein, in particular, as a neuroprotective protein in physiologic and in disease contexts. In ischemia models, induced by permanent middle cerebral artery occlusion, TTR has been shown to be protective, as evidenced by the significant increase in cortical infarction, cerebral edema and the microglial-leukocyte response in mice with TTR deficiency compared with normal TTR levels [51]. Also, TTR deficiency results in spatial reference memory impairment [52]. Other works showed that TTR promotes nerve regeneration and axonal growth $[53,54]$.

In $\mathrm{AD}$, TTR binds to $\mathrm{A} \beta$ preventing its aggregation, accumulation, and toxicity, and facilitating its efflux across the BBB [25]. This barrier is essential to maintain brain homeostasis, however, during normal aging and $\mathrm{AD}, \mathrm{BBB}$ becomes dysfunctional contributing to disease progression. Molecules known to be important for $A \beta$ brain homeostasis, such as LRP-1 and P-gp are reduced, and TTR was previously shown to increase LRP-1

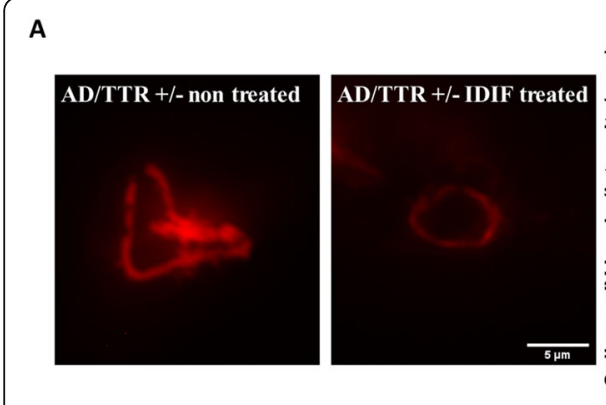

B
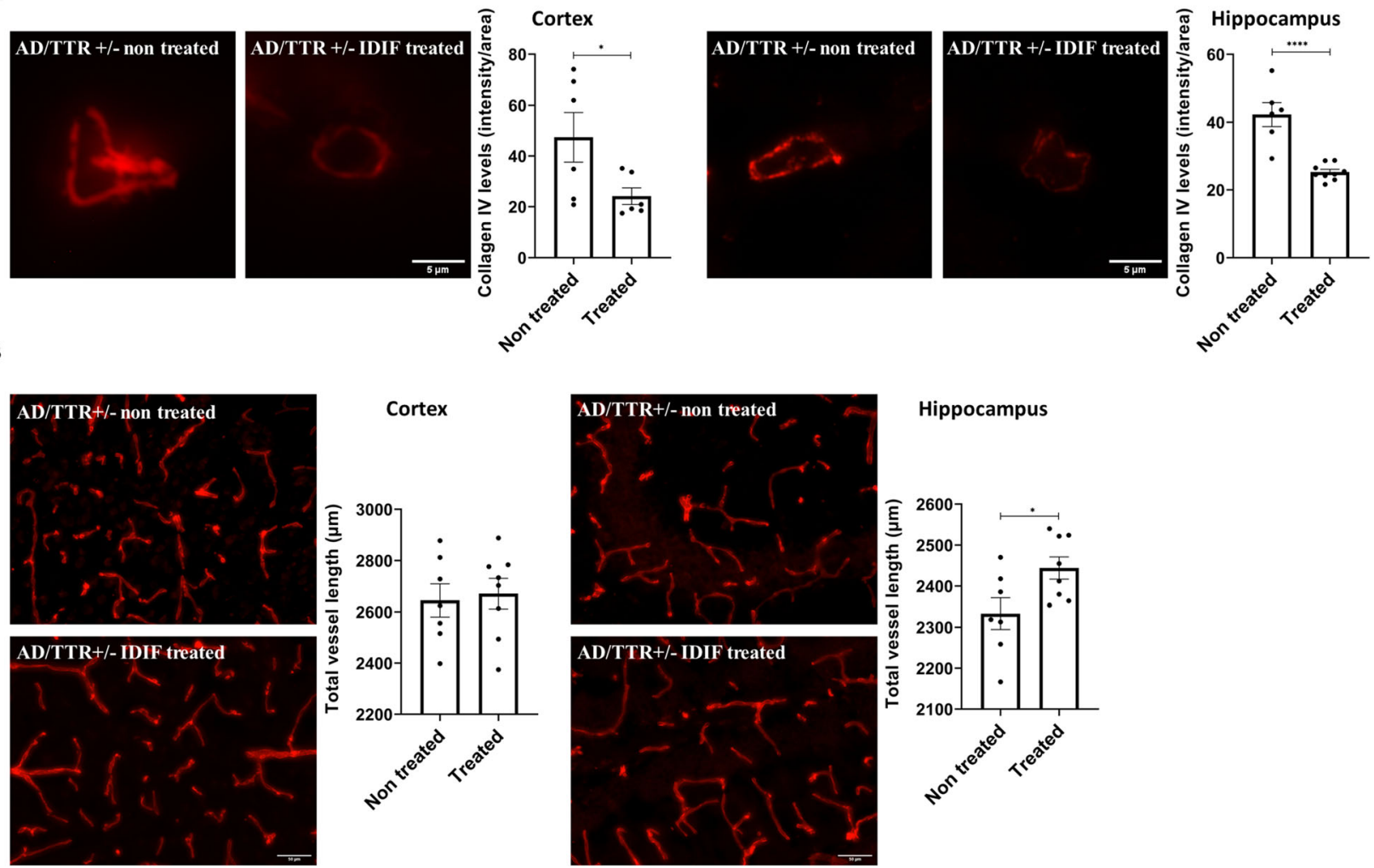

Hippocampus

Fig. 5 Effect of TTR stabilization by IDIF in the thickness of the collagen IV layer and vessel length of AD/TTR+/- mice. A Representative images and quantification plots of collagen IV (red) levels in the BM of cortex and hippocampus vessels derived from 7-month-old AD mice AD/TTR+/mice non-treated ( $n=6$ ), or treated with IDIF (IDIF treated, $n=6$ for cortex; $n=9$ for hippocampus), evidencing a significantly decreased collagen IV layer in treated mice. Scale bar $=5 \mu \mathrm{m}$. B Representative images and quantification plots of the length of brain vessels, as evaluated by collagen IV staining, from 7-month-old AD mice AD/TTR+/- non-treated $(n=7)$ or treated with IDIF (IDIF treated, $n=8)$ showing a significantly increased vessel length in the hippocampus of IDIF treated compared to non-treated mice. Scale bar $=50 \mu \mathrm{m}$. Data are expressed as mean \pm SEM. ${ }^{*} p<0.05 ;{ }^{* * *} p<0.0001$ 
expression in brain ECs and liver [25]. Thus, it is possible that TTR can regulate the neurovasculature in other ways, namely by influencing angiogenesis.

BM thickening through increased collagen IV levels is one such features observed in aging and, more severely, in AD. Previous work by González-Marrero and coworkers described concomitant reduced TTR expression and thickening of the $\mathrm{BM}$ at the choroid plexus (CP), in a triple transgenic mouse model of $\mathrm{AD}$ [55]. In addition, the authors reported increased $A \beta 42$ in epithelial cytosol and in the stroma surrounding choroidal capillaries [55]. Here, we showed that reduction of TTR expression in an AD mouse model influenced not only the BM, resulting in a thicker collagen IV layer both in the cortex and hippocampus, but also vessel length, resulting in decreased vessel length in the hippocampus. To ascertain if the differences were due to a direct or indirect effect of TTR, collagen IV levels were evaluated also in NT 3month-old mice. NT/TTR+/- mice exhibited more collagen IV around brain microvessels than NT/TTR+/+ littermates, suggesting a direct effect of TTR. Comparing the impact of TTR reduction in the thickness of the BM and in vessel length, in the former we found differences both in the hippocampus and in the cortex, while in the later we only found differences in the hippocampus, suggesting that BM thickening precede the decrease in vessel length.

It is not yet clear what leads to increased collagen IV levels in neurovasculature, but these changes are also found in rats suffering from chronic cerebral hypoperfusion $[56,57]$, suggesting that decreased blood flow in the brain leads to high collagen IV content around the vessels. Indeed, diminished cerebral blood flow is an early impact event during AD development [1]. The thickened and rigid vascular wall may slow down nutrient supply and waste elimination, and possibly disturb perivascular drainage. This event along with the formed barrier will potentially contribute to progressive endothelial dysfunction and to an increasing accumulation of $A \beta$ in the brain.

We questioned if the effect of decreased TTR in the $\mathrm{BM}$ and vessel density could be related to TTR participation in angiogenesis, since a number of works implicated TTR in this process, showing that TTR modulates the function of ECs $[43,45]$. TTR is decreased in AD [26-29] but its angiogenic potential was never evaluated in vivo. Using the in vivo CAM assay, we demonstrate that WT TTR, both produced recombinantly and purified from human plasma, influences angiogenesis by promoting the formation of new functional vessels.

Previous works reported TTR angiogenic activity studied in vitro using endothelial cells from different organs (retina, lung, placenta), and here we showed that TTR promotes the formation of capillary-like structures by
hCMEC/D3 cells. This suggests this activity is not limited to TTR from a specific source, although the protein used has been mainly recombinant, including mouse recombinant TTR [45]. It is noteworthy that our work, although using recombinant human TTR and TTR originated from the human liver, also shows that mice that express about half of the protein present brain vascular dysregulation. Whether this effect is produced by circulating TTR that might enter the brain or by CSF-TTR that reaches other brain areas is unknown and further studies are needed. TTR is also synthesized in the pancreas, retina, and placenta, and this locally produced TTR could explain the angiogenic involvement of TTR in other conditions, namely in neovascularization in DR.

We found that VEGF, Ang-2, IL-6, and IL-8 were significantly upregulated in the presence of the protein. VEGF is a major driver of angiogenesis, playing a role in most of the steps of the process. Previous works have suggested a link between TTR and VEGF, and for example, elevated VEGF was found in the vitreous of patients with TTR amyloidosis [58]. Another work, proposed an interaction between the two molecules, although reporting that inhibition of VEGF in branch retinal vein occlusion (BRVO) upregulated TTR [59]. This can be interpreted as an attempt of the cells to restore VEGF levels by increasing TTR, thus corroborating our observations in hCMEC/D3 cells.

Ang-2 was previously found to be upregulated in retinal ECs after treatment with TTR [43] and plays a controversial role in angiogenesis. If, on one hand, it increases migration capacity and tube formation in brain ECs [60], on the other hand, in vivo retinal studies showed that Ang-2 promotes EC death and vessel regression if VEGF is absent. However, when in the presence of VEGF it stimulates an increase in capillary diameter, remodeling of basal lamina, proliferation, and migration of EC [61]. These studies support our findings where TTR promotes an increase of both VEGF and Ang-2, which should result in the promotion of angiogenesis.

The observed upregulation of IL- 8 and IL- 6 is also consistent with an increase in angiogenesis given that IL-8 enhances proliferation, survival, migration, and tube formation $[62,63]$; and IL-6 was shown to induce an increase in EC proliferation, migration and tube formation $[64,65]$.

The importance of TTR in the pathogenesis of AD is also evident when 3-month-old $\mathrm{AD}$ mice are compared to age-matched NT animals, with the same reduction in TTR, showing a thicker BM in the hippocampus of animals with AD. Although this happens prior to amyloid- $\beta$ deposition, we cannot exclude the presence of other $A \beta$ species that can contribute to this increase, and add to the direct effect of TTR observed in the NT mice.

It is not known if the reduction of TTR in AD is a cause or effect of the disease but it is well known that 
TTR stability is key for its activity. Mutations in TTR, associated with amyloidosis, create tetrameric instability leading to dissociation into monomers. TTR stabilization seems also important to prevent pathological changes to the brain vasculature, and for example, heterozygous individuals with TTR T119M allele, which renders a more stable tetramer, have a reduced risk of cerebrovascular disease compared to homozygotes for WT TTR [66]. In $\mathrm{AD}$, TTR stability is decreased, leading to accelerated clearance and consequently, to lower levels. We previously showed that TTR stabilization, achieved through the use of small-molecule compounds, sharing structural similarities with T4 and binding in the TTR central channel, results in improved TTR binding to A $\beta$ [19]. One of those small-molecule stabilizers, IDIF, administrated to our $\mathrm{AD} / \mathrm{TTR}+/$ - mouse model resulted in the amelioration of $\mathrm{AD}$ features $[39,40]$. In this work we showed that IDIF reverted, at least partially, the vascular alterations induced by TTR decrease.

Our results uncover angiogenesis as a mechanism in which TTR participates and importantly, it shows that TTR reduction has an impact in the vascular alterations that occur early in AD with the possibility of recovery upon TTR stabilization.

\section{Limitations}

Our work provides positive and new results but it also reveals some limitations that should be mentioned. Concerning the studies with animals, only females were used, while a final conclusion on the effect of TTR decrease regarding the vascular alterations in $\mathrm{AD}$ may require the use of both genders. The animal model used in this study shows gender-associated modulation of brain $A \beta$ levels by TTR, and females present a more severe AD-like neuropathology [48], which results in a more favorable scenario to assess the involvement of TTR in AD, explaining why we carried out our experiments in females.

\section{Conclusions}

In summary, this work shows that TTR has proangiogenic properties, up-regulating molecules such as IL6, IL-8, Ang-2, and VEGF. TTR is also involved in the early vascular alterations occurring in $\mathrm{AD}$, which may be used as a target for therapeutic intervention in AD.

\footnotetext{
Abbreviations

AD: Alzheimer's disease; BM: Basement membrane; TTR: Transthyretin; NT: Non-transgenic; CAM: Chick chorioallantoic membrane assay; IL: Interleukin; Ang-2: Angiopoietin-2; VEGF: Vascular endothelial growth factor; IDIF: Iododiflunisal; A $\beta$ : Amyloid- $\beta$ peptide; LRP-1: Low-density lipoprotein receptor-related protein 1; BBB: Blood-brain barrier; EC: Endothelial cell; CSF: Cerebrospinal fluid; FAP: Familial amyloid polyneuropathy; T4: Thyroxine; bFGF: Basic fibroblast growth factor; hCMEC/ D3: Human cerebral microvascular endothelial cell line; bEnd.3: Mouse brain endothelial cell line
}

\section{Supplementary Information}

The online version contains supplementary material available at https://doi. org/10.1186/s13195-021-00883-8.

Additional file 1: Figure S1. Analyses of the human recombinant TTR produced in the bacterial expression system. A- SDS-PAGE analysis of two different batches (lanes 2 and 3) showing the monomer as the main form. The dimer is also detected at a much lower extent. Lane 1 refers to the protein standards used and the values refer to the respective molecular weight. B- Western blot analysis of the two different batches (lanes 1 and 2) confirms the identity of TTR. C- Native-PAGE analysis of one of the TTR batches, before (lane 1) or after detoxification (lane 2), shows that a single protein form is detected, corresponding to the tetramer

Additional file 2: Figure S2. Tube formation by hCMEC/D3 cells. Representative images of tube formation by hCMEC/D3 cells. Cells were plated on Matrigel in the absence (negative control, Ctrl-) or presence (positive control, Ctrl+) of bFGF (35 ng/mL) or with $500 \mathrm{nM}$

recombinant TTR, before (TTR non detoxified) or after detoxification (TTR detoxified). Scale bar $=200 \mu \mathrm{m}$. The quantification plot shows that treatment with TTR (either before or after detoxification) results in a significantly higher area covered by the capillary-like structures, than in the negative control. Data are expressed as mean \pm SEM. ${ }^{*} p<0.05 ;{ }^{* *} p$ $<0.01$

\section{Acknowledgements}

The authors acknowledge the support of the i3S Scientific Platforms BioSciences Screening (BS) and Advanced Light Microcopy (ALM), members of the national infrastructure PPBI - Portuguese Platform of Bioimaging (PPBIPOCI-01-0145-FEDER-022122) and of the i3S Animal Facility. The flow cytometry analysis was performed at the Translational Cytometry i3S Scientific Platform with the assistance of E. Cardoso.

\section{Authors' contributions}

$\mathrm{TG}, J \mathrm{~S}$, and JRV performed the experiments; MP was responsible for the CAM assays, and respective analysis and data interpretation; IC was responsible for conception and supervision of the work. IC, TG, JS, and GA discussed the results and wrote the manuscript. All authors read and approved the final manuscript.

\section{Funding}

Grant from Norte2020, Portugal (Norte-01-0145FEDER-000008- Porto Neurosciences) and through a grant from Fundação Millennium bcp.

\section{Availability of data and materials}

All data and material present in this study available upon reasonable request to the corresponding author.

\section{Declarations}

Ethics approval and consent to participate

All the above experiments were approved by the Institute for Research and Innovation in Health Sciences (i3s) Animal Ethics Committee and in agreement with the animal ethics regulation from Directive 2010/63/EU.

\section{Consent for publication}

Not applicable.

\section{Competing interests}

The authors declare that they have no competing interests.

\section{Author details}

${ }^{1}$ i3S - Instituto de Investigação e Inovação em Saúde, Universidade do Porto, Rua Alfredo Allen 208, 4200-135 Porto, Portugal. ${ }^{2}$ IBMC - Instituto de Biologia Molecular e Celular, Universidade do Porto, Rua Alfredo Allen 208, 4200-135 Porto, Portugal. ${ }^{3}$ Instituto de Ciências Biomédicas Abel Salazar (ICBAS), 4050-013 Porto, Portugal. ${ }^{4}$ Faculdade de Medicina, Universidade do Porto, Alameda Prof. Hernâni Monteiro, 4200-319 Porto, Portugal. ${ }^{5}$ IPATIMUP Instituto de Patologia e Imunologia Molecular, Universidade do Porto, Rua Júlio Amaral de Carvalho,45-, 4200-135 Porto, Portugal. ${ }^{6}$ Institut de Química Avançada de Catalunya (I.Q.A.C.-C.S.I.C.), 08034 Barcelona, Spain. 
Received: 11 May 2021 Accepted: 5 August 2021

Published online: 24 August 2021

\section{References}

1. Iturria-Medina Y, Sotero RC, Toussaint PJ, Mateos-Pérez JM, Evans AC, Weiner MW, et al. Early role of vascular dysregulation on late-onset Alzheimer's disease based on multifactorial data-driven analysis. Nat Commun. 2016;7(1):11934. https://doi.org/10.1038/ncomms11934.

2. Donahue JE, Flaherty SL, Johanson CE, Duncan JA, Silverberg GD, Miller MC, et al. RAGE, LRP-1, and amyloid-beta protein in Alzheimer's disease. Acta Neuropathol. 2006;112(4):405-15. https://doi.org/10.1007/s00401-006-0115-3.

3. Vogelgesang S, Cascorbi I, Schroeder E, Pahnke J, Kroemer HK, Siegmund W, et al. Deposition of Alzheimer's $\beta$-amyloid is inversely correlated with $P$ glycoprotein expression in the brains of elderly non-demented humans. Pharmacogenetics. 2002;12(7):535-41. https://doi.org/10.1097/00008571-2 00210000-00005.

4. Daneman R, Prat A. The blood-brain barrier. Cold Spring Harb Perspect Biol. 2015;7(1). https://doi.org/10.1101/cshperspect.a020412.

5. Brown WR, Thore CR. Review: Cerebral microvascular pathology in ageing and neurodegeneration. Neuropathol Appl Neurobiol. 2011;37(1):56-74. https://doi.org/10.1111/j.1365-2990.2010.01139.x.

6. Kisler K, Nelson AR, Montagne A, Zlokovic BV. Cerebral blood flow regulation and neurovascular dysfunction in Alzheimer disease. Nat Rev Neurosci. 2017;18(7):419-34. https://doi.org/10.1038/nrn.2017.48.

7. Biron KE, Dickstein DL, Gopaul R, Jefferies WA. Amyloid Triggers Extensive Cerebral Angiogenesis Causing Blood Brain Barrier Permeability and Hypervascularity in Alzheimer's Disease. PLoS One. 2011;6(8):e23789. https:// doi.org/10.1371/journal.pone.0023789.

8. de la Torre JC, Mussivand T. Can disturbed brain microcirculation cause Alzheimer's disease? Neurol Res. England. 1993;15:146-53.

9. Paris D, Townsend K, Quadros A, Humphrey J, Sun J, Brem S, et al. Inhibition of angiogenesis by $A \beta$ peptides. Angiogenesis. 2004;7(1):75-85. https://doi. org/10.1023/B:AGEN.0000037335.17717.bf.

10. Paris D, Patel N, DelleDonne A, Quadros A, Smeed R, Mullan M. Impaired angiogenesis in a transgenic mouse model of cerebral amyloidosis. Neurosci Lett. 2004;366(1):80-5. https://doi.org/10.1016/j.neulet.2004.05.017.

11. Mancardi GL, Perdelli F, Rivano C, Leonardi A, Bugiani O. Thickening of the basement membrane of cortical capillaries in Alzheimer's disease. Acta Neuropathol. 1980;49(1):79-83. https://doi.org/10.1007/BF00692225.

12. Merlini M, Meyer EP, Ulmann-Schuler A, Nitsch RM. Vascular $\beta$-amyloid and early astrocyte alterations impair cerebrovascular function and cerebral metabolism in transgenic arcAß mice. Acta Neuropathol. 2011;122(3):293311. https://doi.org/10.1007/s00401-011-0834-y.

13. Thal DR, Capetillo-Zarate E, Larionov S, Staufenbiel M, Zurbruegg S, Beckmann N. Capillary cerebral amyloid angiopathy is associated with vessel occlusion and cerebral blood flow disturbances. Neurobiol Aging. 2009; 30(12):1936-48. https://doi.org/10.1016/j.neurobiolaging.2008.01.017.

14. Uspenskaia O, Liebetrau M, Herms J, Danek A, Hamann GF. Aging is associated with increased collagen type IV accumulation in the basal lamina of human cerebral microvessels. BMC Neurosci. 2004;5(1):37. https://doi. org/10.1186/1471-2202-5-37.

15. Bergström J, Gustavsson A, Hellman U, Sletten K, Murphy CL, Weiss DT, et al. Amyloid deposits in transthyretin-derived amyloidosis: cleaved transthyretin is associated with distinct amyloid morphology. J Pathol England. 2005; 206(2):224-32. https://doi.org/10.1002/path.1759.

16. Schwarzman AL, Gregori L, Vitek MP, Lyubski S, Strittmatter WJ, Enghilde J, et al. Transthyretin sequesters amyloid beta protein and prevents amyloid formation. Proc Natl Acad Sci. 1994;91(18):8368-72. https://doi.org/10.1073/ pnas.91.18.8368

17. Costa R, Gonçalves A, Saraiva MJ, Cardoso I. Transthyretin binding to A-Beta peptide - Impact on A-Beta fibrillogenesis and toxicity. FEBS Lett. 2008; 582(6):936-42. https://doi.org/10.1016/j.febslet.2008.02.034.

18. Du J, Murphy RM. Characterization of the interaction of $\beta$-Amyloid with Transthyretin monomers and tetramers. Biochemistry. 2010;49(38):8276-89. https://doi.org/10.1021/bi101280t.

19. Cotrina EY, Gimeno A, Llop J, Jiménez-Barbero J, Quintana J, Valencia G, et al. Calorimetric Studies of Binary and Ternary Molecular Interactions between Transthyretin, A Peptides, and Small-Molecule Chaperones toward an Alternative Strategy for Alzheimer's Disease Drug Discovery. J Med Chem [Internet]. United States; 2020;63:3205-14. Available from: http:// www.ncbi.n/m.nih.gov/pubmed/32124607
20. Li X, Zhang X, Ladiwala ARA, Du D, Yadav JK, Tessier PM, et al. Mechanisms of transthyretin inhibition of $\beta$-amyloid aggregation in vitro. J Neurosci. 2013;33(50):19423-33. https://doi.org/10.1523/JNEUROSCI.2561-13.2013.

21. Nilsson L, Pamrén A, Islam T, Brännström K, Golchin SA, Pettersson N, et al. Transthyretin Interferes with $A \beta$ Amyloid Formation by Redirecting Oligomeric Nuclei into Non-Amyloid Aggregates. J Mol Biol. 2018;430(17): 2722-33. https://doi.org/10.1016/j.jmb.2018.06.005.

22. Palha JA, Moreira P, Wisniewski T, Frangione B, Saraiva MJ. Transthyretin gene in Alzheimer's disease patients. Neurosci Lett. 1996;204(3):212-4. https://doi.org/10.1016/0304-3940(96)12334-X.

23. Schwarzman AL, Goldgaber D. Interaction of transthyretin with amyloid $\beta$ protein: Binding and inhibition of amyloid formation. CIBA Found Symp. 1996:146-64.

24. Cascella R, Conti S, Mannini B, Li X, Buxbaum JN, Tiribilli B, et al. Transthyretin suppresses the toxicity of oligomers formed by misfolded proteins in vitro. Biochim Biophys Acta - Mol Basis Dis. Elsevier B.V. 2013; 1832:2302-14.

25. Alemi M, Gaiteiro C, Ribeiro CA, Santos LM, Gomes JR, Oliveira SM, et al. Transthyretin participates in beta-amyloid transport from the brain to the liver - involvement of the low-density lipoprotein receptor-related protein 1? Sci Rep Nature Publishing Group. 2016;6.

26. Ribeiro CA, Santana I, Oliveira C, Baldeiras I, Moreira J, Saraiva MJ, et al. Transthyretin Decrease in Plasma of $\mathrm{MCl}$ and $\mathrm{AD}$ Patients: Investigation of Mechanisms for Disease Modulation. Curr Alzheimer Res. 2012;9(8):881-9. https://doi.org/10.2174/156720512803251057.

27. Han SH, Jung ES, Sohn JH, Hong HJ, Hong HS, Kim JW, et al. Human serum transthyretin levels correlate inversely with Alzheimer's disease. J Alzheimers Dis. 2011;25(1):77-84. https://doi.org/10.3233/JAD-2011-102145.

28. Velayudhan L, Killick R, Hye A, Kinsey A, Güntert A, Lynham S, et al. Plasma transthyretin as a candidate marker for Alzheimer's disease. J Alzheimers Dis. 2012;28(2):369-75. https://doi.org/10.3233/JAD-2011-110611.

29. Serot JM, Christmann D, Dubost T, Couturier M. Cerebrospinal fluid transthyretin: Aging and late onset Alzheimer's disease. J Neurol Neurosurg Psychiatry. 1997;63(4):506-8. https://doi.org/10.1136/jnnp.63.4.506.

30. Alemi M, Silva SC, Santana I, Cardoso I. Transthyretin stability is critical in assisting beta amyloid clearance- Relevance of transthyretin stabilization in Alzheimer's disease. CNS Neurosci Ther. 2017;23(7):605-19. https://doi.org/1 0.1111/cns.12707.

31. Quintas A, Saraiva MJ, Brito RM. The amyloidogenic potential of transthyretin variants correlates with their tendency to aggregate in solution. FEBS Lett England. 1997;418(3):297-300. https://doi.org/10.1016/ S0014-5793(97)01398-7.

32. Almeida MR, Saraiva MJ. Clearance of extracellular misfolded proteins in systemic amyloidosis: Experience with transthyretin. FEBS Lett. 2012;586(18): 2891-6. https://doi.org/10.1016/j.febslet.2012.07.029.

33. Cardoso I, Goldsbury CS, Müller SA, Olivieri V, Wirtz S, Damas AM, et al. Transthyretin fibrillogenesis entails the assembly of monomers: a molecular model for in vitro assembled transthyretin amyloid-like fibrils. J Mol Biol. 2002;317(5):683-95. https://doi.org/10.1006/jmbi.2002.5441.

34. Almeida MR, Gales L, Damas AM, Cardoso I, Saraiva MJ. Small transthyretin (TTR) ligands as possible therapeutic agents in TTR amyloidoses. Curr Drug Targets CNS Neurol Disord. Netherlands. 2005;4:587-96.

35. Bulawa CE, Connelly S, Devit M, Wang L, Weigel C, Fleming JA, et al. Tafamidis, a potent and selective transthyretin kinetic stabilizer that inhibits the amyloid cascade. Proc Natl Acad Sci U S A. 2012;109(24):9629-34. https://doi.org/10.1073/pnas.1121005109.

36. Almeida MR, Macedo B, Cardoso I, Alves I, Valencia G, Arsequell G, et al. Selective binding to transthyretin and tetramer stabilization in serum from patients with familial amyloidotic polyneuropathy by an iodinated diflunisal derivative. Biochem J. 2004;381(2):351-6. https://doi. org/10.1042/BJ20040011.

37. Baures PW, Oza VB, Peterson SA, Kelly JW. Synthesis and evaluation of inhibitors of transthyretin amyloid formation based on the non-steroidal anti-inflammatory drug, flufenamic acid. Bioorg Med Chem. 1999;7(7):133947. https://doi.org/10.1016/S0968-0896(99)00066-8.

38. Miroy GJ, Lai Z, Lashuel HA, Peterson SA, Strang C, Kelly JW. Inhibiting transthyretin amyloid fibril formation via protein stabilization. Proc Natl Acad Sci U S A. 1996;93(26):15051-6. https:// doi.org/10.1073/pnas.93.26.15051.

39. Rejc L, Gómez-Vallejo V, Rios X, Cossio U, Baz Z, Mujica E, et al. Oral Treatment with lododiflunisal Delays Hippocampal Amyloid- $\beta$ Formation in 
a Transgenic Mouse Model of Alzheimer's Disease: A Longitudinal in vivo Molecular Imaging Study. J Alzheimer's Dis Research Square. 2020;77:99-112.

40. Ribeiro CA, Oliveira SM, Guido LF, Magalhães A, Valencia G, Arsequell G, et al. Transthyretin stabilization by iododiflunisal promotes amyloid- $\beta$ peptide clearance, decreases its deposition, and ameliorates cognitive deficits in an Alzheimer's disease mouse model. J Alzheimers Dis. 2014;39(2): 357-70. https://doi.org/10.3233/JAD-131355.

41. Rios X, Gómez-Vallejo V, Martín A, Cossío U, Morcillo MÁ, Alemi M, et al. Radiochemical examination of transthyretin (TTR) brain penetration assisted by iododiflunisal, a TTR tetramer stabilizer and a new candidate drug for AD. Sci Rep. 2019;9:1-11.

42. Nunes RJ, De Oliveira P, Lages A, Becker JD, Marcelino P, Barroso E, et al. Transthyretin proteins regulate angiogenesis by conferring different molecular identities to endothelial cells. J Biol Chem. 2013;288(44):31752-60. https://doi.org/10.1074/jbc.M113.469858.

43. Shao J, Yao Y. Transthyretin represses neovascularization in diabetic retinopathy. Mol Vis. 2016:22:1188-97.

44. Shao J, Yin Y, Yin X, Ji L, Xin Y, Zou J, et al. Transthyretin Exerts ProApoptotic Effects in Human Retinal Microvascular Endothelial Cells Through a GRP78-Dependent Pathway in Diabetic Retinopathy. Cell Physiol Biochem. 2017:43(2):788-800. https://doi.org/10.1159/000481562.

45. Lee C-C, Ding X, Zhao T, Wu L, Perkins S, Du H, et al. Transthyretin Stimulates Tumor Growth through Regulation of Tumor, Immune, and Endothelial Cells. J Immunol. 2019;202(3):991-1002. https://doi.org/10.4049/ jimmunol.1800736.

46. Borchelt DR, Ratovitski T, Van Lare J, Lee MK, Gonzales V, Jenkins NA, et al. Accelerated Amyloid Deposition in the Brains of Transgenic Mice Coexpressing Mutant Presenilin 1 and Amyloid Precursor Proteins. Neuron. 1997;19(4):939-45. https://doi.org/10.1016/S0896-6273(00)80974-5.

47. Episkopou V, Maeda S, Nishiguchi S, Shimada K, Gaitanaris GA, Gottesman $M E$, et al. Disruption of the transthyretin gene results in mice with depressed levels of plasma retinol and thyroid hormone. Proc Natl Acad Sci U S A. 1993;90(6):2375-9. https://doi.org/10.1073/pnas.90.6.2375.

48. Oliveira SM, Ribeiro CA, Cardoso I, Saraiva MJ. Gender-dependent transthyretin modulation of brain amyloid- $\beta$ Levels: Evidence from a mouse model of Alzheimer's disease. J Alzheimers Dis. 2011;27(2):429-39. https:// doi.org/10.3233/JAD-2011-110488.

49. Furuya H, Saraiva MJM, Alves IL, Gawinowicz MA, Saraiva MJM, Alves IL, et al. Production of Recombinant Human Transthyretin with Biological Activities toward the Understanding of the Molecular Basis of Familial Amyloidotic Polyneuropathy (FAP). Biochemistry. 1991;30(9):2415-21. https://doi.org/10.1 021/bi00223a017.

50. Almeida MR, Damas AM, Lans MC, Brouwer A, Saraiva MJ. Thyroxine binding to transthyretin Met 119: Comparative studies of different heterozygotic carriers and structural analysis. Endocrine. 1997;6(3):309-15. https://doi.org/1 0.1007/BF02820508.

51. Santos $S D$, Lambertsen $K L$, Clausen $B H$, Akinc A, Alvarez $R$, Finsen $B$, et al. CSF transthyretin neuroprotection in a mouse model of brain ischemia. J Neurochem. 2010;115(6):1434-44. https://doi.org/10.1111/j.1471-4159.2010. 07047.x.

52. Sousa JC, Marques F, Dias-Ferreira E, Cerqueira JJ, Sousa N, Palha JA. Transthyretin influences spatial reference memory. Neurobiol Learn Mem. 2007;88(3):381-5. https://doi.org/10.1016/j.nlm.2007.07.006.

53. Fleming CE, Saraiva MJ, Sousa MM. Transthyretin enhances nerve regeneration. J Neurochem. 2007;103(2):831-9. https://doi.org/10.1111/j.14 71-4159.2007.04828.x.

54. Fleming CE, Mar FM, Franquinho F, Saraiva MJ, Sousa MM. Transthyretin internalization by sensory neurons is megalin mediated and necessary for its neuritogenic activity. J Neurosci. 2009;29(10):3220-32. https://doi.org/10.1 523/JNEUROSCI.6012-08.2009.

55. González-Marrero I, Giménez-Llort L, Johanson CE, Carmona-Calero EM, Castañeyra-Ruiz L, Brito-Armas JM, et al. Choroid plexus dysfunction impairs beta-amyloid clearance in a triple transgenic mouse model of Alzheimer's disease. Front Cell Neurosci. 2015;9:1-10.

56. Ueno M, Tomimoto $H$, Akiguchi I, Wakita H, Sakamoto H. Blood-brain barrier disruption in white matter lesions in a rat model of chronic cerebral hypoperfusion. J Cereb Blood Flow Metab. United States. 2002;22:97-104.

57. De Jong Gl, Farkas E, Stienstra CM, Plass JRM, Keijser JN, De La Torre JC, et al. Cerebral hypoperfusion yields capillary damage in the hippocampal CA1 area that correlates with spatial memory impairment. Neuroscience [Internet] 1999;91:203-10. Available from: https://www.sciencedirect.com/
science/article/pii/S0306452298006599, 1, DOI: 10.1016/S03064522(98)00659-9

58. O'Hearn TM, Fawzi A, He S, Rao NA, Lim Jl. Early onset vitreous amyloidosis in familial amyloidotic polyneuropathy with a transthyretin Glu54Gly mutation is associated with elevated vitreous VEGF. Br J Ophthalmol. 2007/ 05/23. BMJ Group. 2007;91:1607-9.

59. Cehofski LJ, Kruse A, Alsing AN, Nielsen JE, Pedersen S, Kirkeby S, et al. Intravitreal bevacizumab upregulates transthyretin in experimental branch retinal vein occlusion. Mol Vis Molecular Vision. 2018;24:759-66.

60. Mochizuki Y, Nakamura T, Kanetake H, Kanda S. Angiopoietin 2 stimulates migration and tube-like structure formation of murine brain capillary endothelial cells through c-Fes and c-Fyn. J Cell Sci. 2002;115(1):175-83. https://doi.org/10.1242/jcs.115.1.175.

61. Lobov IB, Brooks PC, Lang RA. Angiopoietin-2 displays VEGF-dependent modulation of capillary structure and endothelial cell survival in vivo. Proc Natl Acad Sci U S A. 2002;99(17):11205-10. https://doi.org/10.1073/pnas.1 72161899.

62. Dwyer J, Hebda JK, Le Guelte A, Galan-Moya EM, Smith SS, Azzi S, et al. Glioblastoma Cell-Secreted Interleukin-8 Induces Brain Endothelial Cell Permeability via CXCR2. PLoS One. 2012;7(9):e45562. https://doi.org/10.1371/ journal.pone.0045562.

63. Li A, Dubey S, Varney ML, Dave BJ, Singh RK. IL-8 Directly Enhanced Endothelial Cell Survival, Proliferation, and Matrix Metalloproteinases Production and Regulated Angiogenesis. J Immunol. 2003;170(6):3369-76. https://doi.org/10.4049/jimmunol.170.6.3369.

64. Fee D, Grzybicki D, Dobbs M, Ihyer S, Clotfelter J, MacVilay S, et al. Interleukin 6 promotes vasculogenesis of murine brain microvessel endothelial cells. Cytokine. 2000;12(6):655-65. https://doi.org/10.1006/cyto.1 999.0599.

65. Hernández-Rodríguez J, Segarra M, Vilardell C, Sánchez M, García-Martínez A Esteban MJ, et al. Elevated production of interleukin-6 is associated with a lower incidence of disease-related ischemic events in patients with giantcell arteritis: Angiogenic activity of interleukin- 6 as a potential protective mechanism. Circulation. 2003;107(19):2428-34. https://doi.org/10.1161/01. CIR.0000066907.83923.32.

66. Hornstrup LS, Frikke-Schmidt R, Nordestgaard BG, Tybjcrg-Hansen A. Genetic stabilization of transthyretin, cerebrovascular disease, and life expectancy. Arterioscler Thromb Vasc Biol. 2013;33(6):1441-7. https://doi.org/10.1161/A TVBAHA.113.301273.

\section{Publisher's Note}

Springer Nature remains neutral with regard to jurisdictional claims in published maps and institutional affiliations.

\section{Ready to submit your research? Choose BMC and benefit from:}

- fast, convenient online submission

- thorough peer review by experienced researchers in your field

- rapid publication on acceptance

- support for research data, including large and complex data types

- gold Open Access which fosters wider collaboration and increased citations

- maximum visibility for your research: over $100 \mathrm{M}$ website views per year

At BMC, research is always in progress.

Learn more biomedcentral.com/submissions 